This item was submitted to Loughborough's Research Repository by the author.

Items in Figshare are protected by copyright, with all rights reserved, unless otherwise indicated.

\title{
Towards a strategic understanding of global teams and their HR implications: an expert dialogue
}

\section{PLEASE CITE THE PUBLISHED VERSION}

https://doi.org/10.1080/09585192.2018.1428720

\section{PUBLISHER}

(C) Taylor \& Francis

\section{VERSION}

AM (Accepted Manuscript)

\section{PUBLISHER STATEMENT}

This is an Accepted Manuscript of an article published by Taylor \& Francis in The International Journal of Human Resource Management on 8 March 2018, available online:

http://www.tandfonline.com/10.1080/09585192.2018.1428720.

\section{LICENCE}

CC BY-NC-ND 4.0

\section{REPOSITORY RECORD}

Butler, Christina L., Dana Minbaeva, Kristiina Makela, Mary M. Maloney, Luciara Nardon, Minna Paunova, and Angelika Zimmermann. 2019. "Towards a Strategic Understanding of Global Teams and Their HR Implications: An Expert Dialogue”. figshare. https://hdl.handle.net/2134/32398. 


\title{
Towards a strategic understanding of global teams and their HR implications: An expert dialogue
}

\author{
Christina L Butler* \\ Kingston Business School, Kingston University \\ Kingston-upon-Thames, Surrey, KT2 7LB, UK \\ Email: christina.butler@kingston.ac.uk \\ Tel: +44 2087893099 \\ Dana Minbaeva \\ Copenhagen Business School \\ Kilevej 14, DK2000 Copenhagen F, Denmark \\ Email: dm.smg@cbs.dk \\ Tel.: +4538152527 \\ Kristiina Mäkelä \\ Aalto University School of Business \\ P.O. Box 21210 \\ FI-00076 Aalto, Finland \\ Email: kristiina.makela@aalto.fi \\ Tel: +358405593454 \\ Mary M Maloney \\ Opus College of Business, University of St. Thomas \\ 1000 Lasalle Avenue TMH 443 \\ Minneapolis, MN 55403 \\ Email:mary.maloney@stthomas.edu \\ Tel: +1 6519624274 \\ Luciara Nardon \\ Sprott School of Business, Carleton University \\ 926 Dunton Tower, 1125 Colonel By Drive \\ K1S 5B6 Ottawa, Canada \\ E-mail: luciara.nardon@carleton.ca \\ Minna Paunova \\ Copenhagen Business School \\ Kilevej 14, DK2000 Copenhagen F, Denmark \\ Email: dm.smg@cbs.dk \\ Tel.: +4538155662 \\ Angelika Zimmermann \\ School of Business and Economics \\ Loughborough University \\ Loughborough, LE11 3TU, UK \\ E-mail: a.zimmermann@lboro.ac.uk \\ Tel: +44 (0)1509 228845
}

*corresponding author 


\title{
Towards a strategic understanding of global teams and their HR implications:
}

\section{An expert dialogue}

\begin{abstract}
Drawing on initial insights emerging from a panel at the EIBA 2016 Conference in Vienna, here discussants and expert panelists engage in a follow-on conversation ${ }^{\mathrm{i}}$ on the $\mathrm{HR}$ implication of global teams for international organizations. First we set out how HRM can enable global teams and their constituent members to overcome the new and considerable challenges of global teams. These challenges span levels of analysis, time and space. Next we debate global teams as a strategic response to the dual pressures of global integration and local adaptation. We consider what HRM is needed for global teams to successfully resolve this dilemma, challenging practitioners to move beyond the "best practices" and "alignment" dichotomy. Lastly we look to the future to consider implications for research. We propose a rich research agenda focused on the complexities of the global team context.
\end{abstract}

Key Words: Global teams, global virtual teams, international HRM, strategic HRM, strategic alignment, HRM practices

About 25 years ago, researchers began to study multinational teams (Canney Davison, 1994; Earley \& Mosakowski, 2000). These face-to-face teams were comprised of nationals from at least two nationalities. Over time, and paralleling changes in technology, the phenomenon of the global virtual team (GVT) emerged (Davis \& Bryant, 2003). This type of team is comprised of team members from a mix of national backgrounds, but also carries out most or all of its work virtually. More recently, some have adopted the term global team to reflect more closely the current reality of multinational teams in which the mode of work (face-toface or virtual) is not the same for all members and/or constant across time. In this dialogue, we adopt the following definition: "Global teams ... differ from other teams on the following two characteristics: (1) a globally dispersed work environment, and (2) heterogeneity on multiple dimensions” (Zander, Mockaitis \& Butler, 2012, p. 592; Maloney \& Zellmer-Bruhn, 2006). 
We have learned much about managing global teams over the preceding quarter-century. From the outset, research has largely focused on the effectiveness of single global teams (Canney Davison, 1994). The influence of team diversity on performance was an early important research stream (Earley \& Mosakowski, 2000; Maznevski, 1994), but one which continues to debate actively the positives and negatives (Stahl, Mäkelä, Zander \& Maznevski, 2010a) with language diversity an active area of current exploration (Klitmøller \& Lauring, 2012; Tenzer \& Pudelko, 2017). The creative potential of such teams (Doz, Santos, \& Williamson, 2004; Gibson \& Gibbs, 2006) together with influence of social integration processes like trust (Smith et al., 1994) and impact of potentially disruptive processes like conflict (Hinds \& Mortensen, 2005; Jehn \& Mannix, 2001; Joshi, Labianca \& Caligiuri, 2002) on outcomes at the team (Stahl, Maznevski, Voigt \& Jonsen, 2010b) and individual levels (Zimmermann, 2011) have also been studied. Lately researchers have begun to consider how different leadership modes and roles might enhance the performance of global teams (Butler, Zander Mockaitis, \& Sutton, 2012; Zander \& Butler, 2010; Zander, Mockaitis \& Butler, 2012).

However, consideration of the more complex landscape within which global teams now operate suggests new and considerable challenges which span micro through to macro levels from micro through to macro (see Table 1). The first set of challenges is found within teams across time: How do we understand and reap the full range of cognitive and social benefits of the global team experience? How do we develop critical group bonds of responsibility and relationship boundaries with the greater organization, while simultaneously managing the subtle inequalities and failures in meritocracy within a context of growing culturally diversity of national workforces? The next set of challenges reaches across national units across space: How can we manage inter-unit knowledge (i.e., allocating responsibilities and expertise) while concurrently reconciling conflicting interests (e.g., individual career goals) 
situated within national units, all set alongside the well-established communication and coordination challenges of inter-unit working? The final set of challenges is found throughout organizations across time and space: How do we know how to train and develop global team members (and their managers) to work across multiple unknown and often changing boundaries, yet also acknowledge when global teams are the right organizational mechanism to use (and when they are not), while balancing established trade-offs between difference and similarity, proximity and distance, face-to-face working and virtual realities?

The HRM implications of these global teams challenges are yet to be considered; research has not kept pace with practice. Deep understanding of such implications is needed to facilitate the creation of global teams, establish effective management of the global team dynamics and ensure that benefits outweigh the costs associated with global teams. In this dialogue, the discussants approached key experts doing research in this area with a series of questions aimed at identifying the HRM implications of global teams for international organizations. The two discussants are Christina Butler, an expert on the leadership of global teams, and Dana Minbaeva, a leading scholar of strategic international HRM. The five expert panelists are: Kristiina Mäkelä who researches both global and teams and international HRM; Mary Maloney who specializes in the intra-organizational challenges of managing globally dispersed organizations; Luciara Nardon, an intercultural communications expert; Minna Paunova who focuses on national diversity and teamwork; and Angelika Zimmermann, a specialist on global IT teams. Throughout the dialogue we discuss how HRM can enable global teams to overcome the above-described challenges, identify potential solutions for HRM to ensure effectiveness of global teams and push the research agenda forward by presenting theoretical and methodological implications for research on HRM and global teams. 


\section{Looking to the future, how can HRM enable global teams and their constituent members to overcome the inherent challenges of global teams?}

Luciara Nardon: HRM has an important function in the management of global teams given its key role in shaping the context in which teams operate. The proper team context facilitates the leveraging of multiple perspectives that members bring to the table while preventing the larger effort from fragmenting (Bartel \& Garud, 2009). HRM shapes the context of global teams in three essential ways. First, HRM has a critical role in the selection and training of team members with the required skills and characteristics that will facilitate leveraging diversity, such as intercultural communication, intercultural learning and managing emotions and identities (Nardon, forthcoming).

Second, HRM may influence the arrangement of the physical (or virtual) setting to facilitate team dynamics. The location of work or team meetings often influences the team's social dynamics by affecting frames of reference, stress levels, and topics of conversation (Elsbach \& Bechkly, 2007) and guiding people's attention by providing cues as to what is important and what behaviors are expected (Ocasio, 1997). For example, a meeting at headquarters is more likely to focus attention on company needs and home country rules while a meeting at the foreign subsidiary is more likely to focus attention on the local culture and needs. An offsite meeting may call for a more informal interaction and relax some behavioral expectations (Nardon \& Steers, 2014).

Finally, HRM may enable global teams through the careful management of situational strength, which encompasses and expands upon the team membership and situational context. Research on situational strength (Meyer, Dalal \& Hermida, 2010) suggests that cues provided by the external environment concerning the desirability of potential behaviors may override individual preferences. Strong situations put pressures on individuals to behave in certain ways, decreasing behavioral variability and offsetting individual and cultural preferences. For 
example, an individual may have high levels of cultural curiosity and would naturally seek to better understand team members and inquire about their culture - a behavior likely to facilitate understanding. However, the teams' situation may suppress this behavior by placing time constraints, emphasizing similarities, and rewarding task orientation, thus making the expression of curiosity unsafe. There is an opportunity for a careful establishment of rules, procedures, and systems to minimize the effect of individual shortcomings and facilitate team collaboration, but these processes need to be established with caution to avoid stifling creativity and initiative, and favoring one sub-group over another.

Angelika Zimmermann: To follow up on Luciara's point on HRM's key role in shaping the context in which teams operate, let's zoom in on the virtual setting and talk about how HRM could help global teams to overcome challenges embedded in organizational and country contexts. As we know, diverse organizational and country contexts can create conflicting demands for members of global teams, and lead to tensions and power differentials between them (Cohen \& El Sawad, 2007; Levina \& Vaast, 2008; Metiu, 2006). To help global team members to overcome the conflicting demands, HRM needs to be brought closer to strategic management. HR managers will have to work hand in hand with strategic managers, through consultation and joint decision making across functional units, to ensure that the external context is designed in a way to foster favourable internal team dynamics.

I will illustrate this by an example from my own area of research, global teams within offshoring settings (Zimmermann \& Ravishankar, 2014; 2016). Offshoring - the transfer of work to internal or external providers in an offshore location - is a common organizational context where members of different countries (onshore and offshore) have to work as part of a global team. Offshoring often creates competing interests between team members, in particular when it comes to attractive tasks and career prospects. Fears of losing tasks can result in a lack of support of the offshoring operation by onshore members, entailing 
decreased work motivation and non-satisfactory task performance on the side of offshore members, which can further stifle onshore members' motivation to transfer tasks to the offshore members. Such vicious circles can however be avoided if the distribution of tasks between onshore and offshore sites creates sufficient career prospects for onshore as well as offshore team members, and if sufficient time is allocated for recruitment and training to ensure satisfactory performance by offshore members. In practice, decision makers are often not fully aware of such motivational dynamics and tend to focus primarily on the potential cost savings through offshoring. HR managers can thus take an important role in emphasizing the motivational foundations of the global team in an offshoring setting. HR managers should collaborate with strategic managers to ensure that the distribution of tasks and responsibilities is not only cost-driven, but is also motivating with regard to career prospects, realistic in terms of available skills offshore, and communicated clearly to employees at all levels. Without such input by HR managers, strategic managers are less likely to pay sufficient attention to the necessary motivational foundations of offshoring, which can result in suboptimal implementation and success of the firm's offshoring strategy.

Minna Paunova: In addition to the challenges outlined by Angelika, there is another mounting challenge: how to make the best out of national and cultural diversity "at home”? With progressively complex migration patterns, HRM needs to look beyond more traditional North-South HQ-subsidiary models, and address the challenges of multiplex adaptation in highly diverse (i.e., "superdiverse”: Vertovec, 2007) workplaces at their doorstep. This is particularly pressing these days, given the palpable rise of anti-immigration sentiment, and the nativist turn in party politics in the US and all across Europe. Organizations will be affected, and may need to take a stance-willingly or unwillingly. Public discourse has centered on the refugee crisis (2015- ) and undocumented migrants, but the large majority of international migrants in the world-people residing in a country other than their country of 
birth—are documented migrant workers. In recent years, their number has been the highest ever recorded, and migration flows have been unprecedentedly polydirectional (IOM, 2015).

In addition to offshoring, the challenges of which Angelika just described very well, much of international HRM research is about the challenges of expatriates. The truth is that migration from the developed North to the developing South (i.e., that includes the traditional expatriate model) makes a mere 5\% of the total international migrant stock. However, international migrants do make up approximately one third of the total population in cities such as Sydney, Auckland, Singapore and London, Amsterdam, Frankfurt and Paris (IOM, 2015). In these cities and others, global (collocated) teams comprising multiple nationalities will be ever more commonplace. Global collocated teams can already be found in MNEs, of course, but also university departments, startups, and even some SMEs.

HRM should expect that highly diverse global teams and binational teams look substantially different (Haas \& Cummings, 2014; Tröster \& van Knippenberg, 2012), and think outside the "us vs. them” (home vs. host, local vs. foreign, etc.) box of two-country teams. In truly global teams at home and elsewhere, conflict and inequality are equally likely to hinder effective teamwork but perhaps more likely to remain unseen. Global models of work tend to be Western, taken for granted, and dominate in these teams (Pudelko \& Harzing, 2007; Spence, Dambrin, Carter, Husillos, \& Archel, 2015). This may possibly undermine mutual adaptation, exclude some staff from decision-making, and potentially diminish the value of diversity. Despite their comparable qualifications and experience, nationals from less developed countries tend to exert less influence in global teams (Paunova, 2016). In addition to attending to the abovementioned dynamics, HRM may consider facilitating the multiplex adaptation of all parties involved, be they locals or miscellaneous migrants. Unbiased staffing is a necessary but not sufficient condition to enable global teams. Global teams naturally necessitate training that is more than “cross-cultural”. Their members certainly benefit from 
training programs geared towards intercultural mindfulness. I believe they also increasingly need tools for exerting and withholding influence in the global workplace. Such training programs—and research base that upholds them—-may still need to be developed.

Let's talk a little bit more about MNE context and focus on implications for international human resource management (IHRM) and international business (IB) research. Previous research showed that global teams play crucial role in dealing with dual pressures of global integration and local adaptation. What HRM is needed for global teams successfully resolving this dilemma?

Kristiina Mäkelä: For organizations, issues related to coordination become increasingly important. Given that global teams are the preferred means of horizontal coordination for many firms today, employees increasingly work in many different teams at the same time (Zaccaro, Marks, \& DeChurch, 2012). The management of such multiple team systems bring new HR challenges for both organizations and individuals.

Firms will likely need to individualize, streamline and simplify their HRM practices. Currently, HR is typically organized along unit and employee-group boundaries, with firms seeking to globally standardize or locally adapt their HRM to varying degrees (Pudelko \& Harzing, 2007; Rosenzweig \& Nohria, 1994). Such boundaries become increasingly blurred in a team-based organization, where individual employees are more likely to work with colleagues from other groups than their own (Zander et al., 2012) - with the consequence that the key tension may no longer be that between global standardization versus local adaptation, but perhaps rather global standardization versus team-based or even individualized practices.

Staffing, performance management and talent management may take the shape of portfolios, in addition to careers. For example, when employees' work consist of multiple team/project assignments rather than one main job, this makes traditional yearly performance management processes difficult or even obsolete. Employees will have different objectives for each team/project, and also likely perform differently in each. This inevitably means more individualized performance management systems; we will need to move away from yearly 
processes into more real-time, immediate planning and feedback cycles for each project. What is more, if we need separate performance management for each project, then current relatively heavy processes must be significantly simplified and streamlined.

Finally, multiple team assignments compete for individual employees' time, commitment and effort, which they need to navigate and prioritize. This requires new competencies: selfmanagement and social interaction skills become more important, as will network management skills. We need to recruit and train experts who also have some understanding of other fields in a T-shaped way, can orchestrate collaboration, and influence without authority.

Mary Maloney: I agree with Kristiina that global teams are currently a very common coordination mechanism in MNEs. Is it possible teams are too commonly used? Perhaps MNEs could accomplish coordination for some tasks more efficiently and effectively using a different integrative mechanism. In addition to the HRM actions Kristiina suggests, perhaps an additional role HRM can play is advising management about the types of tasks that are best suited to global teams. Deploying teams when it is not optimal to do so is likely to be costly, inefficient, and leave members frustrated.

To illustrate, Kim, Park and Prescott (2003) conducted a study comparing different integrative mechanisms - people-based (teams, but also transfers, training, communities of practice); information-based (intranet, data management); formalization-based (policies and procedures); and centralization-based (top down decision-making). While they found that people and information integrative mechanisms tend to be more effective than formalization and centralization overall, they also found that some integrative mechanisms are best suited to particular functional tasks. For example, information and centralization were more effective in the marketing function than people and formalization. HRM can play a role in 
identifying which people-based mechanisms are best suited to a particular task, and identifying when non-people mechanisms might be more efficient for the MNE.

I want to note that there is not a lot of research in this area to guide us. That is partly because it is difficult to design studies comparing integrative mechanisms, and partly because disciplinary divides separate researchers investigating phenomena at the firm level and at the team level. Team researchers don't often research the times when teams aren't necessary!

Now you named various HRM policies and practices - selection and training, managing social dynamics, working with diversity, and supporting motivation, performance and talent management - that could potentially enable global teams to overcome their challenges. Aren't all these practices already placed firmly on the agenda of any worldclass HRM function today in any international organization? What exactly should HRM focus when dealing with global teams? Should the focus be on "best practice" (Becker \& Huselid, 1998) or on the problem of “alignment” (Huselid \& Becker, 2011)?

Minna Paunova: You are probably right that many of these practices are already in place. As Kristiina suggested, firms will likely need to streamline and simplify these, not the opposite. The complexity of the issue HRM faces (i.e., highly complex diversity) may require universal “best practices” before attempting “alignment” — and anyway a certain level of HRM quality is required to facilitate alignment (Becker \& Huselid, 1998; Huselid \& Becker, 2011). At the micro HRM level, in terms of managing a diverse workforce working in global teams, two questions can be raised (Just, 2004): (1) How are various cultural identities preserved and allowed expression within the common setting of the workplace?; and (2) How does the diversified workforce come to work together, reaching common decisions and taking collective action? In other words, should HRM seek to protect existing differences between employees by giving various privileges and rights to different groups, or should HRM seek to promote commonality? The answers to these questions give two conflicting perspectives on international and diversity management. HRM has to (and can) simultaneously protect differences and promote commonality_perhaps by starting with the later (Just, 2004). One 
way to do so, and related to Luciara's earlier point about situational strength, is specifically through emphasizing the common situation (see also, e.g., Hornsey \& Hogg, 2000). In terms of HRM practices more broadly, promoting commonality may require shifting attention back to the universals in human motivation and values. But universal systems have to be designed to account for the paradox of meritocracy (Castilla \& Banard, 2010) and address managerial biases in recruitment, selection, performance appraisal, rewards systems, and termination.

Luciara Nardon: In our recent research on innovative organizations (Nardon, Grant \& Wang, 2016), my colleagues and I concluded that the "best practices" approach understates the importance of the unique context facing teams and organizations. Through a critical review of the literature, we found that innovation may emerge through different processes, mechanisms, and structures (Westwood \& Low, 2003) and the congruence or incongruence among cultural elements (Baker, Sinkula, Grinstein, \& Rosenzweig, 2014; Baumard, 2014; Homburg \& Pflesser, 2000) as well as how cultural elements are demarcated to address a particular problem (Leonardi, 2011) are as important as the cultural elements themselves in fostering team and organizational innovation.

Drawing from this research, I argue that HRM research need to focus on increased contextualization of HRM practices. Organizations are faced with unique internal and external demands (e.g. legal compliance requirements, social expectations, task characteristics), and resources and constraints (e.g. financial capital, human capital, structural capital, and social capital). These demands and constraints are subjectively perceived and may result in different outcomes depending on the skills, attitudes, and behaviors of organization members (Edge \&MacLaine, 2015). Assembling the "best" strategies and practices alone is insufficient because it ignores the unique context facing the organization. Rather, HRM practices must address objective and subjective constraints facing the team and the organization, acknowledging the complex relationship between different aspects of the 
national, organizational and team contexts. Thus, “alignment” suggests the need of a team culture and practices that are uniquely positioned to address the organizational context, including the objective and subjective demands and constraints facing the team and the tangible and intangible resources available to team members.

Angelika Zimmermann: I see the tension between "best practices” and "alignment” somewhat differently. In my view, the problem of alignment has become more prominent with the rise of global teams, even though best practice HRM remains important. To realise the benefits of global teams, the management of these teams' human resources needs to be aligned not merely with the firm's business strategy (e.g. low cost or innovation) and operational strategies, as suggested by Becker and Huselid (1998) and Huselid and Becker (2011), but also with the firm's global strategy. One such strategy is the offshoring strategy I referred to in my previous example, others concern the firm's global set-up at various stages of internationalisation, ranging from foreign entry to the creation of a global network of national units that act as equal partners.

HRM can help to motivate global team members to support the desired global set-up of the firm. By ensuring that the international distribution of tasks and career options is attractive for team members in different countries, HR managers can incite members to allocate tasks internationally in line with the global strategy, share knowledge between national units, create international personal networks, and achieve global integration and learning, and thereby put the firm's global strategy into practice. Several other aspects of the HR architecture should also be designed to foster such international collaboration motivation. Intercultural training and staff exchange are common best practice here, but HRM can also take part in creating strong situations that encourage cultural curiosity, as Luciara pointed out, and foster global team members' general motivation to work across cultures. Explicit 
targets and rewards for intercultural cooperation (e.g. rewards for extra effort spent on training international colleagues) may create such strong situations.

Importantly, the degree to which a firm's global strategy requires national units to be interdependent can vary. With it, the degree to which global team members need to be encouraged to interact internationally has to vary as well. The HRM architecture hence needs to be aligned with the particular global strategy. Alignment is also important for HR investments into top talent, which needs to be differentiated according to the strategic relevance of certain positions in the firm (Huselid \& Becker, 2011). In a global firm, strategic managers will have to decide which of the international units holds what strategic position, and invest accordingly. In the case of offshoring, for example, a strong focus on cost benefits may cloud managers' judgment of the potential strategic role of offshore sites (e.g. innovative IT development in India), resulting in a low career ceiling for their offshore members. HR managers should here consult with strategic managers on the strategic potential of different units, and help them design talent management practices that match different units’ potential. Mary Maloney: As Angelika notes, the degree to which a firm's global strategy requires national units to be interdependent can vary. An aligned HRM architecture would support the use of global teams in key areas of global integration, and perhaps employ other mechanisms in where there is less interdependence. Just as Huselid and Becker (2011) propose that there are strategic jobs, there are also likely to be strategic global teams. HR support could take the form of recruiting, selecting and training people where global teams are particularly strategic, and also provide guidance about alternative organizational mechanisms when a task is not integrative enough to warrant the use of a global team. As Huselid and Becker (2011) suggest, micro-macro disciplinary bridging will be required to expand our understanding here. 
In addition, sometimes we forget that teams do more than just accomplish tasks. Teams, especially global teams, can also be a vehicle for cross-boundary learning and social capital development among team members. This fits in Huselid and Becker’s (2011) category of best practice. For example, HR could include global team experience in training and development plans for new employees as a way to build product knowledge and an organizational network.

Kristiina Mäkelä: To me, the HR question for global teams is not about either-or - i.e., either best practices (Becker \& Huselid, 1998) or alignment (Huselid \& Becker, 2011) - but rather both-and. As I suggested earlier, today’s HR practices are typically organized by location, being standardized or locally adapted to different degrees (Pudelko \& Harzing, 2007; Rosenzweig \& Nohria, 1994). For teams this means that potential issues arise when the local HR practices that team members are subjected to, differ between the team members. Performance management is particularly problematic in this regard: different performance criteria may lead to conflicting goals, expectations and mindsets between team members, and consequently, to lower team-performance (Mäkelä et al., 2017).

To remedy this important pitfall, team-based organizations need to have a globally standardized base of policies and best practices that are shared by everyone. In terms of performance management, for example, these should include transparent processes and values-based evaluation criteria that facilitate procedural and distributive justice (e.g., Biron et al., 2011). To complement these common policies, local circumstances will likely require local adaptations, but the difference is that these may no longer be location-bound but rather team-specific.

This will ensure greater cohesiveness within teams, but potentially lead to many different HRM practices to be followed in each location. Yet, given that work will likely be both more individualized and less bound to a specific place in the future (Gartner, Mäkelä, Sumelius, \& Vuorenmaa, 2017), this may be a lesser coordination issue. Nevertheless, it is important that 
team-based organizations have processes that ensure that different goals and expectations are shared and aligned upfront at the beginning of each team assignment (Zander, Zettinig, \& Mäkelä, , 2013).

So, after a decade of research on global teams should we change our view of HRM? Do global teams require a different understanding of HRM?

Minna Paunova: But there are very many views on HRM already (Buyens \& De Vos, 2001). Among these, I would claim HRM's foremost role is as an agent of positive, generative organizational and societal change. Through global team management, HRM can help shape a better global society.

In terms of HRM practices, it could be that our academic view is lagging behind what is happening out there. Some organizations already implement more individualized, team- and project-based performance management systems, to return to Kristiina's earlier point. But I think we have much to learn about the challenges and effectiveness of these. One way to think of HRM has long been as coach and consultant, despite the also cynical view of "hiring, firing, compensation”. World-class HRM considers carefully the challenges of global teams and works to guide line managers and individual team members to make the best use of "human capital”.

Here, we must also question the notion of human capital, which has become associated with HRM. Diversity and human differences found in global teams are not orthogonal to human capital; they are tightly interconnected in ways. Holding measurable forms of human capital constant, social class (Ashley \& Empson, 2013) and nationality (Paunova, 2016), among other differences between team members, carry notions of higher or lower human capital, associating with ideas about individual members' worth and contributions, and biasing an otherwise "best practices" system. Perceived and not necessarily actual human capital can have marked implications on organizational members' careers, on their positions in and 
outside teams, and ultimately, perhaps, on the use organizations make of diversity and global teams.

HRM's role is of course to coach and train managers to overcome these issues of strategic HRM “implementation”. But it's important not to let pressures to legitimize HRM as a core strategic function undermine the idea that HRM has an obligation to employees. To be provocative, I would even claim that the view of HRM as somehow subordinate to strategy lies in the very notion of "human resources". Going forward, we may question this view not only with respect to global teams and their members, but also more broadly in management.

What kind of research questions should dominate the research agenda of those aiming at pushing the frontiers of HRM and global teams research?

Mary Maloney: One way we can push frontiers is to look beyond the team task and time boundaries that usually circumscribe our work. Researchers tend to study what makes teams more effective by looking inside them. This is laudable work and should be continued, but looking to the future maybe it is time to take a step back and examine when, where and why global teams are deployed in the first place. This requires teams researchers to look upward and span system levels -- team to firm, and disciplines -- organizational behavior to strategy (Maloney, Bresman, Zellmer-Bruhn \& Beaver 2016). Yet, for an HR manager at an MNE these differences are literally academic. Ideally, research would help HRM guide managers and organizations toward the best applications of global teams, in addition to helping them address the challenges that come up once the team is in place.

Another avenue for future research is learning more about the full range of what teams deliver to organizations. The degree to which teams accomplish their assigned task is the most commonly studied form of team effectiveness. But the impact of a global team on the organization does not stop there. Relationships are built on the team that outlast the team (Maloney, Shah \& Zellmer-Bruhn, 2015); knowledge sharing results as a by-product of 
global team interaction (Mäkelä \& Brewster 2007); socialization occurs that may help strengthen organizational culture; learning takes place that affects the next team and the next project; and likely more. A wide-angle lens on team effectiveness, which taps into organizational impacts beyond task accomplishment, might be able to guide HRM to more strategically deploy global teams in the future. For example, HR could include global team experience in training and development plans for new employees as a way to build product knowledge and an organizational network.

Angelika Zimmermann: To build on what Mary has said, from this dialogue, it has become very clear how complex the boundaries and the dynamics of global teams have become. Global teams function within different global set-ups that are tied to different stages of internationalisation, they can include members of multiple nationalities that entail particular power and status differentials (as Minna indicates), and their members are often part of multiple teams, as Kristiina has pointed out. All this creates a web of interests and incentives that is hard to grasp. Somewhat in contrast to Minna's view, I believe that it is still valuable to study teams that are composed of only two or a few nationalities, because this makes it easier to isolate fundamental socio-cognitive processes and context factors, which may also apply in more complex settings. However, a more challenging task will be to study how various influences interact in the case of more complex global team compositions and more multifaceted organizational and country contexts. This will require in-depth case study research that describes idiosyncratic contexts, in line with Luciara's suggestions. The higher level aim will then be to arrive at more generic insights into the interactions between various contexts, team compositions, and other aspects of complexity in global teams.

Luciara Nardon: I would like to bring us back the challenge of accidental versus designed-in multiculturalism. At the beginning of this dialogue Minna raised the need to better understand co-located multicultural teams caused by migration as opposed to a purposeful 
selection of individuals representing HQ and subsidiaries. Most of the literature on global teams is based on the assumption that the teams are multicultural by design and different nationalities and cultural backgrounds are representative of organizational operations. However, as Minna argued, many local teams are multicultural due to migration patterns challenging the usability of cross-cultural frameworks for both research and training. It is imperative that IHRM move towards intercultural perspectives, which involve more complex and situationally dependent understandings of the role of culture and context on behavior and recognizes the interactive dynamic between the behaviors of individuals and the team context they experience (Nardon, forthcoming). Furthermore, research in HRM and global teams need to become more process oriented and focus on how team cultures and practices unfold overtime.

In realizing this research agenda that you identified, what theoretical contributions and disciplines should we be "borrowing" from (Oswick et al., 2011)? And in advancing this agenda, how do we get from "borrowing" to "blending" (Oswick et al., 2011)?

Angelika Zimmermann: From a research perspective, it is important to combine insights from diverse disciplines including social psychology, organizational behaviour, strategic management, international business, and information systems (a discipline that has researched global IT development teams for some while). Such an interdisciplinary approach can help researchers to take a broader view on global teams and their HR management, going beyond the study of internal team dynamics and considering their interactions with the team's organizational and country context.

Luciara Nardon: I agree with Angelika that research at the intersection of HRM and global teams can benefit from interdisplinary approaches drawing on theoretical lenses from psychology, sociology, cognitive science, communication studies and information technology. Communication theories may be of particular relevance to the study of teams. Teams depend on interpersonal communication for achieving tasks, defining group 
boundaries and relating to the rest of the organization, establishing bonds, or mutual understanding of responsibilities and belonging, and agreeing on norms and practices within the team (Eliasoph \& Lichterman, 2003; Cole, 2015). In that sense, borrowing theories from communication may help us better understand the communication processes that facilitate performance. Moreover, by blending insights from theories of organizing and communication, perspectives such as Communication as Constitutive of Organizations (CCO) (e.g. Schoeneborn, Blaschke, Cooren, McPhee, Seidl, \& Taylor, 2014) may help shed light on the role of communication in the development of teams and their impact on the organizations to which they belong.

\section{What kind of important methodological issues should we be taking into consideration?}

Mary Maloney: Much of our past research has been cross-sectional and within team only, so new insights will come from longitudinal and cross-level designs, and by employing network analysis. By their nature teams are dynamic entities (Cronin, Weingart \& Todorova 2011). So to fully understand global teams, and to address many of the issues discussed in this dialogue, we will have to engage in longitudinal research. For example, my co-authors and measured perceptions of similarity among team members at different times and found that these perceptions are not static (Zellmer-Bruhn, Maloney, Bhappu \& Salvador 2005). In other research, we explore the lasting effects of the team experience on team members, and find that relationships formed in teams (even those among people from different nationalities) persist after teams disband (Maloney, Shah, Zellmer-Bruhn, 2015). We used network analysis to explore patterns in dyadic relationships within an organizational network, comparing dyads sharing a team experience to those that did not. Network analysis can be a useful tool in investigating relationships within teams, between teams, with external actors, and over time.

Kristiina Mäkelä: As Luciara suggested earlier, teams always operate in a context. To me, the question of how to better integrate context into our models is a crucial element going 
forward. Current research is still predominantly focusing on team-internal issues, such as trust, conflict, diversity and leadership, and their influence on team-outcomes (e.g., Stahl et al., 2010b). I would like to see contextual issues such as stakeholders, boundaries, and crossteam memberships taken into account to a much greater extent than we do now (Butler, et al., 2012, Zander et al., 2012).

One way of doing this would be multilevel modeling (Mäkelä et al., 2014). To be fair, a lot of teams research is already taking the nested nature of teams into account, in that we incorporate both individual- and team-level variables into our models. The next step would be to either add contextual variables into our existing models, or even start to build three-level models. In the first option, we would simply add variables that tap into the context in a more comprehensive way, including constructs such as team members' involvement in other teams at the individual level, or the number of stakeholders (internal or external) or boundaries the team faces at the group level. The second option would be to add another layer, and start examining teams and their members in their organizational contexts in a three-level model. This would allow us to include organizational level factors, such as multi-team systems. This, of course, requires more work in planning and executing larger research initiatives - but would take empirical teams-research to the next level.

Where do we see the biggest contribution of the future work on global teams: IB literature or (international) HRM?

Minna Paunova: HRM and especially organizational behavior issues are still overlooked in much of the IB literature. Research on global teams therefore has real potential for a strong contribution to the IB field. Again, this should be done in a way that does not subordinate global teams to global strategy. Instead, we may also consider the societal realities that give rise to global teams sometimes independently of strategy. In terms of HRM research and practice, the use of global teams opens a brand new window of opportunity to make a 
positive difference for people and the organizations that employee them in the face of globalization.

Kristiina Mäkelä: Again, I don’t see this as an either-or but rather a both-and question. Crosssemination of fields will contribute to both, just in different ways. And it may not be only a matter of contribution, but also a necessity: If we believe that team-based organizing is the way of the future, then understanding the intersection becomes vital - how does HRM best support effective teamwork and multiteam systems, and what kind of HRM is required for teams. So, in terms of research contributions, I think both fields would benefit from incorporating research from the other.

In terms of theoretical and practical implications, however, I would say teams come first. A longstanding argument in the HRM field is that of 'fit', referring to the need for firm to "align their various HRM practices toward their strategic goal and that practices must complement one another to achieve the firm's business strategy” (Bowen \& Ostroff, 2004, p. 203). If we apply this strategic perspective to the teams context, we must start from what we are trying to achieve. The second question then becomes what kinds of capabilities we need to achieve the strategic objectives: for example, team-based organizing will enable firms to combine diverse knowledge and expertise in a flexible way in a changing environment. Only then can we decide what kinds of HRM practices will best enable us to attain the objectives and capabilities. This is not to say that one is more important than the other, but rather to highlight the sequence of decision making - and the HR function will, of course, have a big role to play in building and staffing the teams-based organizing structure in the first place. 


\section{Towards a rich research agenda: Enlarging our understanding of context}

As we began this dialogue among experts, we identified three sets of new and considerable challenges which need to be understood if HR practitioners and their organizations are truly to benefit from global teams.

The first of three sets of challenges was positioned within teams across time. Here our discussion has helped us to identify important tensions between accidental and designed-in multiculturalism, and the need to uncover the subtleties inherent in micro team contexts. Our experts call for more advanced understanding of HRM in global team research: seeing HRM as being intertwined with strategy-making process (Andersen \& Minbaeva, 2013), keeping a strong focus on strategy implementation (De Cieri \& Dowling, 2012) and ensuring a strong signaling effect throughout organization (Bowen \& Ostroff, 2004). Our experts stressed the important role of HRM in shaping the context in which global team operate. In doing so, HR managers should carefully manage the situational strength of the HRM system to avoid: decreasing within-group behavioral variability (i.e. simultaneously protect differences and promote commonality); to avoid offsetting individual and cultural preferences; and creating conflicting demands for multicultural members of global teams.

The second set of challenges was set across national units across space. Our experts offered several examples of how global teams could be used as coordination mechanisms, especially in MNE context. They also warn about a potential overuse of global teams for coordination purposes that could result in negative outcomes for organizations (it could be costly, ineffective and create frustration among global team members). Although benefits of using global teams for coordination are obvious, they become much more effective when used in combination with information-based and centralization-based mechanisms. The role of HRM then is to recognize the value of global teams and use them as a strategic human capital resource for organizational competitive advantage (Ployhart et al., 2014). 
Through conversation we highlighted the importance of global teams for intra-organizational knowledge sharing and learning, effective organizational boundary spanning, social capital development and innovation. We identified several HRM practices that are particularly conducive for managing global teams and that create conditions under which organizational benefits outweigh the costs associated with global teams. We also encouraged HRM researchers and practitioners to avoid focusing too much on "best practices" and move beyond "one-size-fits-all” thinking by looking at strategic alignment, searching for fit (incorporating both contingency and configurational approaches and creating differentiated architecture for managing global teams (Paawee \& Farndale, 2012; Becker \& Huselid, 2006; Huselid \& Becker, 2011)).

The final challenge was conceived throughout organizations across time and space. We questioned whether belonging to global teams and managing them require new competencies, new ways of leading and different demands for being led. Our experts pointed out the importance of self-management, social interaction skills, intercultural skills, ability to work both face-to-face and across distance, etc. The search for new competencies has implications for "breadth and depth" of human capital pool from which we recruit for global team, how we organize, lead and develop global teams.

Overall, the experts have drawn a very rich research agenda. Throughout our discussion, they were clearly promoting a research agenda that includes both-and rather than either-or. To realize this rich agenda, the experts pointed out the importance of building on knowledge from multiple disciplines - social psychology, cognitive science, strategic management, information systems, etc. We would like to stress that "borrowing" theories from those disciplines is beneficial only if "what is being borrowed will explain something better than it has been heretofore explained” (Whetten, Felin \& King, 2009: 541). We also encourage future research to "shift from theory generation premised on a unidirectional process of 
borrowing to a two-way process of correspondence based on the notion of "conceptual blending” (Oswick et al., 2011: 318). Two-way blending will push the researchers out of their “comfort zone” and make them look beyond team task, question team boundaries and nottake-for-granted team composition.

Finally, to advance the work on global teams and HRM we should avoid simplifying the context. In fact "rather than seeking to simplify the world, they [developed theories] should become more complex to better cope with organizational complexity” (Tsoukas, 2017: 136). We need more context-rich rather than context-free research. Unfortunately, while the heterogeneity of the context in global teams is now often acknowledged, it is seldom used as an input for theory development (Minbaeva, 2016). Doing justice to organizational complexity will also allow researchers to grasp the logic of practice, generate findings which impact on the practice of HRM, and promote lasting connections between research and practice. 


\section{References}

Andersen, T., \& Minbaeva, D. (2013). Human resources in strategy making. Human Resource Management, 52(5), 809-827.

Ashley, L., \& Empson, L. (2013). Differentiation and discrimination: Understanding social class and social exclusion in leading law firms. Human Relations 66, 219-244.

Baker, W. E., Sinkula, J. M., Grinstein, A., \& Rosenzweig, S. (2014). The effect of radical innovation in/congruence on new product performance. Industrial Marketing Management, 43(8), 1314-1323.

Bartel, C. A. \& Garud, R. (2009). The role of narratives in sustaining organizational innovation. Organization Science, 20(1), 107-117.

Becker, B. E., \& Huselid, M. A. (1998). High performance work systems and firm performance: A synthesis of research and managerial implications. Research in Personnel and Human Resource Management, 16, 53-101.

Biron, M., Farndale, E. \& Paauwe, J. (2011). Performance management effectiveness: lessons from world-leading firms. The International Journal of Human Resource Management, 22, 1294-131.

Bowen, D.E. \& Ostroff, C. (2004), "Understanding HRM-firm performance linkages: The role of the strength of the HRM system”, Academy of Management Review, Vol. 29(2), 203-221.

Butler C.L, Zander L, Mockaitis A.I., \& Sutton C. (2012). The Global Leader as Boundary Spanner, Bridge Maker and Blender. Industrial Organizational Psychologist: Perspectives on Science and Practice, 5(2), 246-243.

Buyens, D., \& De Vos, A. (2001). Perceptions of the value of the HR function. Human Resource Management Journal, 11(3), 70-89.

Castilla, E. J., \& Benard, S. (2010). The paradox of meritocracy in organizations. Administrative Science Quarterly, 55(4), 543-676.

Canney Davison, S. (1994). Creating a high performance international team, The Journal of Management Development, 13, 81-90.

Cohen, L. \& El-Sawad, A. (2007). Lived Experiences of Offshoring: An examination of UK and Indian financial service members' accounts of themselves and one another. Human Relations, 60(8): 1235-1262.

Cole, B. M. (2015). Lessons from a martial arts dojo: A prolonged process model of highcontext communication. Academy of Management Journal, 58(2), 567-591.

Cronin, M. A., Weingart, L. R., \& Todorova, G. (2011). Dynamics in groups: Are we there yet?. Academy of Management Annals, 5(1), 571-612.

De Cieri, H., \& Dowling, P.J. 2012. Strategic human resource management in multinational enterprises: Developments and directions. In G. Stahl, I. Björkman and S. Morris, (Eds.) Handbook of international HRM research (2nd edn.). Cheltenham UK: Edward Elgar.

Davis, D.D., \& J.L. Bryant (2003). Influence at a distance: Leadership in global virtual teams, Advances in Global Leadership, 3, 303-340. 
Doz, Y., Santos, J., \& Williamson, P. (2004). Diversity: The key to innovation advantage. European Business Forum, 17, 25-27.

Earley, P.C. \& E. Mosakowski (2000). Creating hybrid team cultures: An empirical test of transnational team functioning, Academy of Management Journal, 43(1), 26-49.

Eliasoph, N., \& Lichterman, P. (2003). Culture in interaction. American Journal of Sociology, 108(4), 735-794.

Elsbach, K. D. \& Bechkly, B. A. (2007). It's More than a Desk: Working Smarter through Leveraged Office Design. California Management Review, 49.2: 80-101.

Felin, T., Foss, N. J., \& Ployhart, R. E. (2015). The Microfoundations Movement in Strategy and Organization Theory. The Academy of Management Annals, 9(1), 575-632.

Gartner, J., Mäkelä, K., Sumelius, J. \& Vuorenmaa, H. (2017) “Brave New HR? The Changing nature of work and the management of human resources. Paper presented the Academy of Management Annual Conference in Atlanta, Aug 4-8, 2017.

Gibson, C.B., \& Gibbs, J.L. (2006). Unpacking the Concept of Virtuality: The Effects of Geographic Dispersion, Electronic Dependence, Dynamic Structure, and National Diversity on Team Innovation. Administrative Science Quarterly, 51(3), 451-495.

Grandori, A., \& Kogut, B. (2002). Dialogue on Organization and Knowledge, Organization Science, 13(3), 224-231.

Haas, M. R., \& Cummings, J. N. (2014). Barriers to knowledge seeking within MNC teams: Which differences matter most? Journal of International Business Studies, 46, 36-62.

Hinds, P., \& Mortensen, M. (2005). Understanding Conflict in Geographically Distributed Teams: The Moderating Effects of Shared Identity, Shared Context, and Spontaneous Communication. Organization Science. 16 (3), 290-307.

Hornsey, M. J., \& Hogg, M. A. (2000). Assimilation and diversity: An integrative model of subgroup relations. Personality and Social Psychology Review 4(2), 143-156.

Huselid, M. \& Becker, B. (2011). Bridging Micro and Macro Domains: Workforce Differentiation and Strategic Human Resource Management. Journal of Management, 37(2), 421-428.

IOM (2015). Global migration trends factsheet. Berlin: International Organization for Migration.

Jehn, K. A., \& Mannix, E. A. (2001). The dynamic nature of conflict: A longitudinal study of intragroup conflict and group performance. Academy of Management Journal , 44(2), 238-251.

Joshi, A. Labianca, G., \& Caligiuri, M. (2002). Getting along long distance: understanding conflict in a multinational team through network analysis, Journal of World Business, 37(4), 277-284.

Just, S. (2004). Communicative prerequisites for diversity-protection of difference or $\begin{array}{llll}\text { promotion of } & \text { Commonality. Intercultural Commication } 7\end{array}$ http://immi.se/intercultural/nr7/just.htm

Kim, K., Park, J-H, \& Prescott, J. E. (2003) "The global integration of business functions: A study of multinational businesses in integrated global industries." Journal of International Business Studies, 34(4), 327-344. 
Klitmøller, A., \& Lauring, J. (2012). When global virtual teams share knowledge: Media richness, cultural difference and language commonality, Journal of World Business, 48(3), 398-406.

Leonardi, P. M. (2011). Innovation blindness: Culture, frames, and cross-boundary problem construction in the development of new technology concepts. Organization Science, 22(2), 347-369.

Levina, N. \& Vaast, E. (2008). Innovating or Doing as Told? Status differences and overlapping boundaries in offshore collaboration, MIS Quarterly, 32(2), 307-332.

Mäkelä, K., \& Brewster, C. (2009). Interunit interaction contexts, interpersonal social capital, and the differing levels of knowledge sharing. Human Resource Management, 48(4), 591-613.

Mäkelä, K., Ehrnrooth, M., Smale, A. \& Sumelius, J. (2014): "Designing and implementing multi-actor and multi-level research projects”. In Sanders, K., Cogin, J. A. \& Bainbridge, H.T.J. (Eds.) Research methods for Human Resource Management, Routledge.

Mäkelä, K., Lauring, J., Butler, C.L., Lee, H-Y., Lehrvik, J.E., Luencke, G., Miska, C., Pahlberg, C. \& Stahl, G. (forthcoming): "Meeting the challenges of globalization: Implications for Teams and Team Leadership". Forthcoming in Zander, L. (Ed.): Edward Elgar Research Handbook of Global Leadership: Making a difference. Edwar Elgar.

Maloney, M. M., Bresman, H., Zellmer-Bruhn, M. E., \& Beaver, G. R. (2016). Contextualization and context theorizing in teams research: A look back and a path forward. Academy of Management Annals, 10(1), 891-942.

Maloney, M. M., Shah, P. P., \& Zellmer-Bruhn, M.E. (2010). The lasting imprint of teams: Project teams and intra-organizational network formation. In Academy of Management Proceedings (Vol. 2010, No. 1, pp. 1-6). Academy of Management.

Maloney, M.M., \& Zellmer-Bruhn, M. (2006). Building bridges, windows, and cultures: Mediating mechanisms between team heterogeneity and performance in global teams, Management International Review, 46, 697-720.

Maznevski, M.L. (1994). Understanding our Differences: Performance in Decision-making groups with diverse members, Human Relations, 47(5), 531-552.

Metiu, A. (2006). Owning the Code: status closure in distributed groups. Organization Science, 17(4), 418-435.

Meyer, R. D., Dalal, R. S., \& Hermida. R. (2010). A Review and Synthesis of Situational Strength in the Organizational Sciences. Journal of Management, 36(1), 121-140.

Minbaeva, D. (2016) Contextualizing the individual in international management research: Black boxes, comfort zones and A future research agenda. European Journal of International Management, 10(1): 95-104

Nardon, L. Working in a multicultural world: A guide for developing intercultural competence, University of Toronto Press, forthcoming.

Nardon, L., Grant, G. \& Wang, Y. (2016). “Socio Cognitive Influences on Innovation” Social Sciences and Humanities Research Council (SSHRC) Knowledge Synthesis Report. 
Nardon, L. \& Steers, R. M. (2014). Managing cross-cultural encounters: putting things in context. Organizational Dynamics, 43, 138-145.

Ocasio, W. (1997). “Towards and attention-based view of the firm”. Strategic Management Journal, 18, 187-206.

Oswick, C., Fleming, P. \& Hanlon, G. (2011). From borrowing to blending: Rethinking the process of organizational theory building. Academy of Management Review, 36(2), 318-337

Paawe, J., \& Farndale, E. 2012. International human resource management and firm performance. In G. Stahl, I. Björkman and S. Morris, (Eds.) Handbook of international HRM research. (2nd edn.) Cheltenham UK: Edward Elgar.

Paunova, M. (2016). Who gets to lead the multinational team? An updated status characteristics perspective. Human Relations. Online before print, doi: $10.1177 / 0018726716678469$.

Ployhart, R., Nyberg, A., Reilly, G., \& Maltarich, M. 2014. Human capital is dead. Long live human capital resources! Journal of Management, 40, 371-398.

Pudelko, M., \& Harzing A. W. (2007). Country-of-origin, localization, or dominance effect? An empirical investigation of HRM practices in foreign subsidiaries. Human Resource Management, 46: 535-559.

Rosenzweig, P., \& Nohria, N. (1994), "Influences on human resource management practices in multinational corporations”, Journal of International Business Studies, Vol. 25 No.2, pp. 229-252.

Schoeneborn, D., Blaschke, S., Cooren, F., McPhee, R. D., Seidl, D., \& Taylor, J. R. (2014). The Three Schools of CCO Thinking Interactive Dialogue and Systematic Comparison. Management Communication Quarterly, 28(2), 285-316.

Smith, K. G., Smith, K. A., Olian, J. D., Sims Jr, H. P., O'Bannon, D. P., \& Scully, J. A. (1994). Top management team demography and process: The role of social integration and communication. Administrative Science Quarterly, 39 (3), 412-438.

Spence, C., Dambrin, C., Carter, C., Husillos, J., \& Archel, P. (2015). Global ends, local means: Cross-national homogeneity in professional service firms. Human Relations, 68: 765-788.

Stahl, G.K., Mäkelä, K., Zander,L., Maznevski, M.L. (2010a). A look at the bright side of multicultural team diversity, Scandinavian Journal of Management, 26(4), 439-447.

Stahl, G., Maznevski, M., Voigt, A., \& Jonsen, K. (2010b). Unraveling the effects of cultural diversity in teams: A meta-analysis of research on multicultural work groups. Journal of International Business Studies, 41, 690-709.

Tenzer, H, \& Pudelko, M. (2017). The influence of language differences on power dynamics in multinational teams, Journal of World Business, 52(1), 45-61.

Tröster, C., \& van Knippenberg, D. (2012). Leader openness, nationality dissimilarity, and voice in multinational management teams. Journal of International Business Studies, 43,591-613.

Tsoukas, H. 2017. Don’t simplify, complexify: From disjunctive to conjunctive theorizing in organization and management studies. Journal of Management Studies, 54(2), 132153. 
Vertovec, S. (2007). Super-diversity and its implications. Ethnic and Racial Studies, 30(6), 1024-1054.

Westwood, R., \& Low, D. R. (2003). The multicultural muse culture, creativity and innovation. International Journal of Cross Cultural Management, 3(2), 235-259.

Whetten, D., Felin, T., \& King, B. The practice of theory borrowing in organziational studies: Current issues and future directions. Journal of Management, 35(3), 537-563.

Zaccaro, S.J., Marks, M.A. \& DeChurch, L. (2012). Multiteam Systems: An organizational form for dynamic and complex environments. New York: Routledge.

Zander, L. (2004). Editorial: Dialogue on identifying culture, International Journal of Crosscultural Management, 4(3), 275-290.

Zander, L., \& Butler, C.L. (2010). Leadership Modes: Success strategies for multicultural teams, Scandinavian Journal of Management, 26(3), 258-267.

Zander, L., Zettinig, P. \& Mäkelä, K. (2013): “Leading Global Virtual Teams to Success”. Organizational Dynamics, 42(3), 228-237.

Zander, L., Mockaitis, A., \& Butler, C.L. (2012). Leading Global Teams, Journal of World Business, 47(4), 592-603.

Zellmer-Bruhn, M. E., Maloney, M. M., Bhappu, A. D., \& Salvador, R. B. (2008). When and how do differences matter? An exploration of perceived similarity in teams. Organizational Behavior and Human Decision Processes, 107(1), 41-59.

Zimmermann, A. (2011). Collaborative IT offshoring relationships and professional role identities: Reflections from a field study, Journal of Vocational Behavior, 78(3), 351360.

Zimmermann, A., \& Ravishankar, M.N. (2014). Knowledge Transfer in IT Offshoring Relationships: The roles of social capital, efficacy, and outcome expectations. Information Systems Journal, 24(3), 167-202.

Zimmermann, A., \& Ravishankar, M.N. (2016). A Systems Perspective on Offshoring Strategy and Motivational Drivers amongst Onshore and Offshore Employees. Journal of World Business, 51(4), 548-567. 
${ }^{i}$ This dialogue is inspired by similar pieces in the special issues of other journals (Grandori \& Kogut, 2002; Zander, 2004). 